\title{
Power Quality Improvement of Constant Frequency Aircraft Electric Power System Using Genetic Algorithm and Neural Network Control Based Control Scheme
}

\section{Saifullah Khalid*}

Department of Electrical Engineering, IET Lucknow, India

\begin{abstract}
Synchronous Reference Frame Strategy for extracting reference currents for shunt active power filters have been modified using Artificial Neural Network, Genetic Algorithm based controller and their performances have been compared. The acute analysis of Comparison of the compensation capability based on THD and speedwell be done, and recommendations will be given for the choice of technique to be used. The simulated results using MATLAB model are shown, and they will undoubtedly prove the importance of the proposed control technique of aircraft shunt APF.
\end{abstract}

Keywords: Aircraft electrical system; Shunt Active Filter (APF); Synchronous reference frame strategy; ANN; Genetic algorithm; THD

\section{Introduction}

More advanced aircraft power systems [1-3] have been needed due to increased use of electrical power on behalf of other alternate sources of energy. The subsystems like flight control, flight surface actuators, passenger entertainment, are driven by electric power, which flowingly increased the demand for creating aircraft power system more intelligent and advanced. These subsystems have extensive increased electrical loads i.e. power electronic devices, increased feeding of electric power, additional demand for power, and above to all of that great stability problems.

In peculiarity to standard supply system, the source frequency is of $50 \mathrm{~Hz}$, whereas, aircraft AC power system works on the source frequency of $400 \mathrm{~Hz}$ [1-3]. Aircraft power utility works on source voltage of $115 / 200 \mathrm{~V}$. The loads applicable to the plane a system differs from the loads used in $50 \mathrm{~Hz}$ system [1]. When we deliberate the generation portion; aircraft power utility will remain AC driven from the engine for the plane primary power. Novel fuel cell technology can be used to produce a DC output for ground power, and its silence process would match up to suitably with the Auxiliary Power Unit (APU). Though when considering the dissemination of primary power, whether $\mathrm{AC}$ or DC; each approach has its merits. In DC distribution, HVDC power distribution systems permit the most resourceful employ of generated power by antithetical loss from skin effect. This allows paralleling and loads sharing amongst the generators. In AC distribution, AC Flogging is very clear-cut at high levels too. Due to its high dependence on HVDC system, a wide range of Contactors, Relays can be exploited.

While talking about Aircraft Power Systems we also need to consider increased power electronics application in aircraft which creates harmonics, large neutral currents, waveform distortion of both supply voltage and current, poor power factor, and excessive current demand. Besides if some non-linear loads is impressed upon a supply, their effects are additive. Due to these troubles, there may be nuisance tripping of circuit breakers or increased loss and thermal heating effects that may provoke early component failure. This is a prodigious problem to every motor loads on the system. Hence, decent power quality of the generation system is of scrupulous attention to the Aircraft manufacturer. We discern that aircraft systems work on high frequency so even on the higher frequencies in the range of 360 to 900 $\mathrm{Hz}$; these components would remain very significant.
Today, advanced soft computing techniques are used widely in the involuntary control system, and optimization of the system applied. Several of them are such as Fuzzy logic [4-8], optimization of active power filter using GA [9-12], power loss reduction using particle swarm optimization [13], Artificial neural network control [14-18] applied in together machinery and filter devices.

In this paper, ANN based and Genetic Algorithm optimized have been used together to mend the complete performance of active filter for the lessening of harmonics and other delinquents created into the aircraft electrical system because of the non-linear loads [1]. The simulation results clearly show their effectiveness. The simulation results acquired with the new model are much improved than those of traditional method.

The paper has been modified in a sequential manner. The APF outline and the load under contemplation are discussed in Section II. The control algorithm for APF converses in Section III. MATLAB/ Simulink based simulation results are presented in Section IV, and finally Section V concludes the paper [19-23].

\section{System Depiction}

The aircraft power system is a three-phase power system with the frequency of $400 \mathrm{~Hz}$. As exposed in Figure 1, Shunt Active Power Filter improves the power quality and compensates the harmonic currents in the system [22,24-28]. The shunt APF is comprehended by using one voltage source inverters (VSIs) connected at the point of common coupling (PCC) to a common DC link voltage [20-23].

The set of loads for aircraft system consist of three loads. The first load is a three-phase rectifier in parallel with an inductive load and an

*Corresponding author: Saifullah Khalid, Department of Electrical Engineering, IET Lucknow, India, Tel: +91-522-2361692; Fax: +91-522-236163; E-mail: saifullahkhalid@Outlook.com

Received October 07, 2016; Accepted November 21, 2016; Published November 28, 2016

Citation: Khalid S (2016) Power Quality Improvement of Constant Frequency Aircraft Electric Power System Using Genetic Algorithm and Neural Network Control Based Control Scheme. J Electr Electron Syst 5: 206. doi:10.4172/2332 0796.1000206

Copyright: (c) 2016 Khalid S. This is an open-access article distributed under the terms of the Creative Commons Attribution License, which permits unrestricted use, distribution, and reproduction in any medium, provided the original author and source are credited. 
unbalanced load connected in a phase with the midpoint (Load 1). The second one is a three phase rectifier connects a pure resistance directly (Load 2). The third one is a three-phase inductive load linked with the ground point (Load 3). Finally, a combination of all three loads connected with system together at a different time interval to study the effectiveness of the control schemes has been used to verify the functionality of the active filter in its ability to compensate for current harmonics. For the case of all three load connected, Load 1 is always connected, Load 2 is initially connected and is disconnected after every 2.5 cycles, Load 3 is connected and disconnected after every half cycle. All the simulations have been done for 15 cycles. The circuit parameters are given in last section - Parameters.

\section{Control Theory}

The proposed control of APF depends on Synchronous Reference Frame Strategy, and it has been optimized using artificial intelligent technique like artificial Neural Network and Genetic Algorithm together. Synchronous Reference Frame strategy has been discussed in brief in this section. The following section also deals with the primary application of ANN and GA in the control schemes [19,20].

\section{Synchronous reference frame strategy (SRF)}

The reference frame $\mathrm{d}-\mathrm{q}$ is decided by the angle $\theta$ on the $\mathrm{d}-\mathrm{q}$ frame applied in the $\mathrm{p}-\mathrm{q}$ theory. Slight modifications are required in the conventional SRF method so that they can be used in aircraft power utility and compensate well the neutral current. For this reasons, the zero-sequence component of current has not been well thought-out. So, the zero sequence subtract block cart from the zero sequence current. The positive sequence and negative sequence component are obtained in output current. After its park transformation, only instantaneous active and reactive current are available in the output current in the

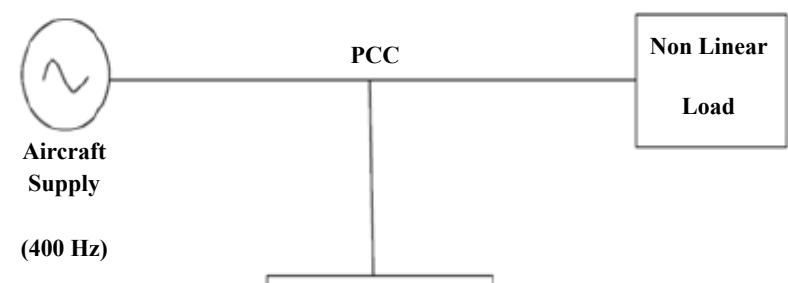

Shunt Active Power Filter

Figure 1: Aircraft system using shunt active power filter. d-q frame. A low-pass filter accomplishes the disunion of the dc and ac factor of the active current for compensation of the reactive and harmonic current. This active current goes through a low-pass filter, and the signal came from dc voltage regulator together though a Park counter-transformation subtracting from the load currents generates the reference current. Reference current is generated (Figure 2).

\section{Application of ANN based control}

In this paper, Synchronous reference frame Strategy has been modeled by an artificial neural network (ANN) made up of two hidden layers with 10 neurons each, and one output layer with 3 neurons. The logarithmic activation function is the base of the two hidden layers neurons, and linear activation function for the output layer neurons.

As shown in Figure 3, the ANN has seven inputs $\left(\mathrm{v}_{\mathrm{a}}, \mathrm{v}_{\mathrm{b}}, \mathrm{v}_{\mathrm{c}}, \mathrm{dc}\right.$ voltage error, $\left.i_{a}, i_{b}, i_{c}\right)$ and three outputs $\left(i_{r a}, i_{r b}, i_{r c}\right)$ as observed in the different strategies. The adaptation of the weights (W) and bias (b) in the ANN, is based, first, on the computation of the mean square error (MSE) between the outputs of the PQ technique and those of the ANN, and secondly, on the execution of 'Levenberg-Marquardt backpropagation' algorithm.

The reference current generation unit and dc voltage controller unit has been modeled and their individual and simultaneous effect has been observed.

\section{Application of genetic algorithm}

Genetic algorithm (GA) is a search technique used in computing [9] to find an optimal solution for a search problem. It is implemented as a computer simulation in which a population of abstract representations (called chromosomes of the genome) of candidate solutions (individuals) to an optimization problem evolves [11] towards improved solutions. In general, the fittest individuals of any population tend to reproduce and survive to the next generation, thus improving the successive generations [12]. Commonly, the algorithm terminates when either a maximum number of generations has been produced, or a satisfactory fitness level has been reached for the population [12]. The fitness function is defined over the genetic representation and measures the quality of the represented solution. The fitness function is always problem dependent [11]. By starting at several independent points and searching in parallel, the algorithm avoids local minima and also avoids converging to sub optimal solutions. In this way, GAs have been shown to be capable of locating high performance areas in complex domains without experiencing the difficulties associated with high dimensionality, as may occur with gradient decent techniques or methods that rely on derivative information [15].

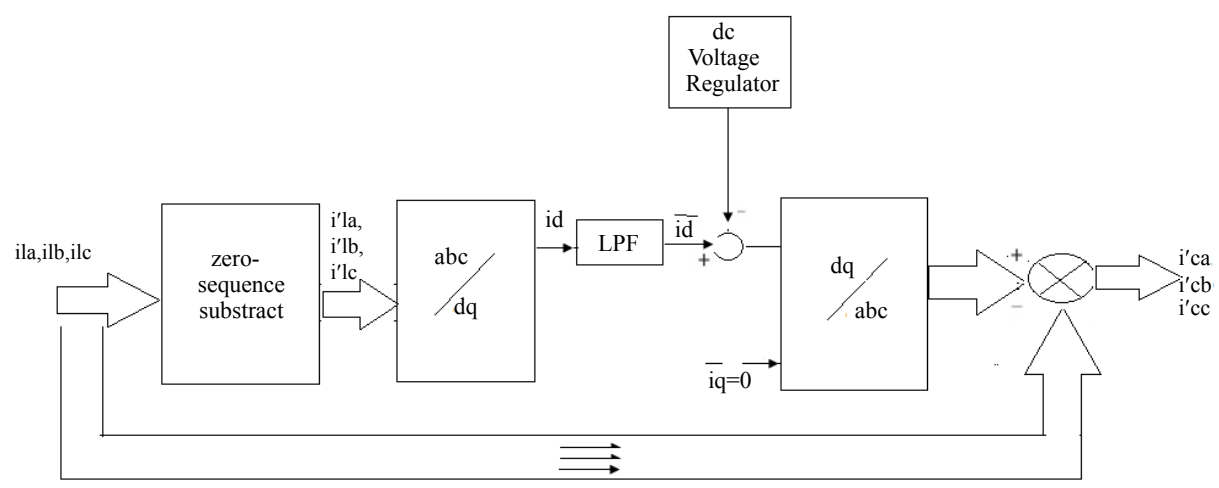

Figure 2: Control block diagram of the shunt active filter using synchronous reference frame strategy. 


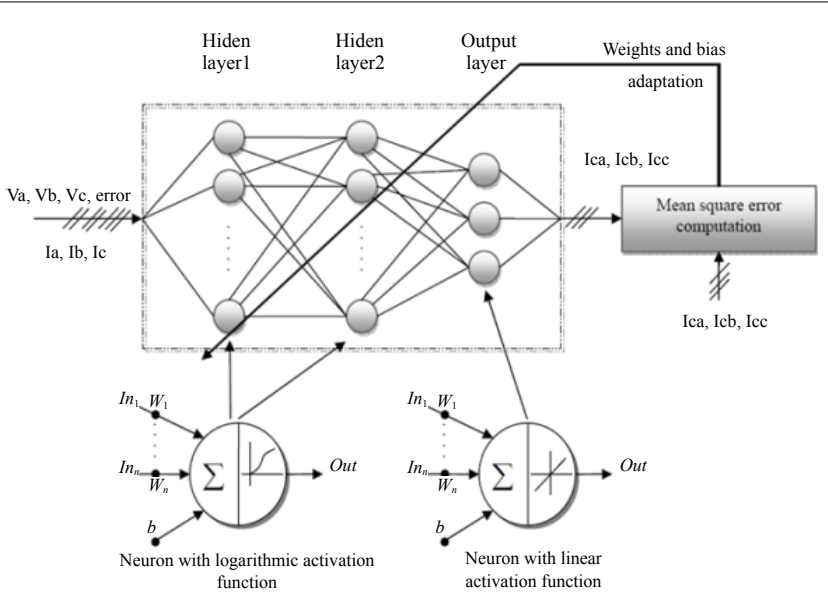

Figure 3: Artificial neural network for modeling.

Most of the published papers use this generalized program to fit their objective function but after the popularity of MATLAB as software for simulation and modeling researchers have started using genetic algorithm optimization tool (GAOT) available. MATLAB provides many built in auxiliary functions useful for function optimization [15]. GAOT is not only easy to implement but is faster in simulating.

In this paper, the GA is applied to determine value of inductor filter $\left(\mathrm{L}_{\mathrm{f}}\right)$. GA will try to search the best value of the filter inductor. Supply side has been taken as input side for inductor filter. Inductor filter value used in this thesis is $0.25 \mathrm{mH}$. Offline, computer simulation using MATLAB Simulink has been applied to find out the optimum value for inductor filter.

For the program, the limits, inequality and bounds need to be defined. This paper has attempted to develop a single GA code program for optimizing objective function.

$$
\begin{aligned}
& \mathrm{x} 0=\left[\mathrm{V}_{\mathrm{dc}} ; \mathrm{V}_{\mathrm{s}} ; \mathrm{I}_{\mathrm{c}} ; \mathrm{t} ; \mathrm{L}_{\mathrm{f}}\right] \\
& \mathrm{lb}=\left[\mathrm{V}_{\mathrm{dcmin}} ; \mathrm{V}_{\text {smin }} ; \mathrm{I}_{\mathrm{cmin}} ; \mathrm{t}_{\text {min }} ; \mathrm{L}_{\mathrm{fmin}}\right] \text {; } \\
& \mathrm{ub}=\left[\mathrm{V}_{\mathrm{dcmax}} ; \mathrm{V}_{\text {smax }} ; \mathrm{I}_{\text {cmax }} ; \mathrm{t}_{\max } ; \mathrm{L}_{\text {fmax }}\right] \text {; } \\
& \text { Aeq=[]; } \\
& \text { beq=[]; }
\end{aligned}
$$

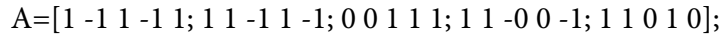

$$
\begin{aligned}
& \mathrm{b}=\text { [Values of } \mathrm{V}_{\mathrm{dc}} ; \mathrm{V}_{\mathrm{s}} ; \mathrm{I} ; \mathrm{t} ; \mathrm{L}_{\mathrm{f}} \text { depending upon the equations]; } \\
& \text { [x, fval, exitflag]=fmincon(@myobj,x0,A,b,Aeq,beq,lb,ub). }
\end{aligned}
$$

The boundary and limits of parameters in the filter has been defined using the data of ANN model. The data has been collected using MATLAB/Simulink. Finally, a program using genetic algorithm has been written to generate the best value of the filter inductor. After the calculation, GA generates the value of $0.187 \mathrm{mH}$. After using this inductor value, total harmonic distortion of source current and voltage have been reduced so we can say that inductor value calculated is optimum.

\section{Simulation Results and Discussions}

The proposed scheme of APF is simulated in MATLAB environment to estimate its performance. Three loads have been applied together at a different time interval to check the affectivity of the control schemes for the reduction of harmonics. A small amount of inductance is also connected to the terminals of the load to get the most effective compensation. The simulation results clearly reveal that the scheme can successfully reduce the significant amount of THD in source current and voltage within limits.

\section{Uncompensated system}

Figure 4 shows the waveforms obtained after the simulation of an uncompensated system. It has been observed that the THD of source current calculated when loads connected with the system is $9.5 \%$ and THD of source Voltage were $1.55 \%$. By observing these data, we can easily recognize supply has been polluted when loads have been connected and is obviously not within the limit of the international standard.

\section{Compensated system}

The performance of APF under different loads connected, when utilizing ANN Control has been discussed below for the control strategy given below.

For synchronous reference frame strategy: From Figure 5 it has been empiric that that the THDs of source current and source voltage were $2.82 \%$ and $1.65 \%$ respectively. The compensation time was $0.01 \mathrm{sec}$. At $\mathrm{t}=0.01 \mathrm{sec}$, it is apparent that the waveforms for source voltage and source current have become sinusoidal. Figure 5 shows the waveforms of compensation current, DC capacitor voltage, and load current.

The aberration in dc voltage can be acutely apparent in the waveforms. As per claim for accretion the compensation current for accomplishing the load current demand, it releases the energy, and after that it accuses and tries to achieve its set value. If we carefully observe, we can acquisition out that the compensation current is, in fact, accomplishing the appeal of load current, and afterward the active filtering the source current and voltage is affected to be sinusoidal.

For synchronous reference frame strategy using ANN and genetic algorithm: THDs of source current and source voltage have been found $2.62 \%$ and $1.03 \%$ respectively after making observations from the simulation results shown in Figure 6 . The waveforms for source voltage and source current have become sinusoidal at $\mathrm{t}=0.0068$ sec. Compensation time is $0.0068 \mathrm{sec}$. The waveforms of compensation current, dc capacitor Voltage, and load current have been shown in
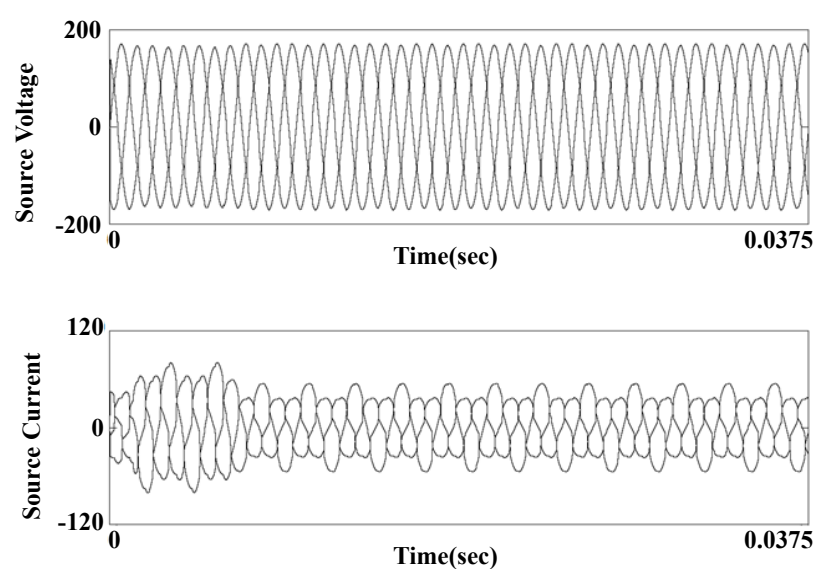

Figure 4: Source voltage and source current waveforms of uncompensated system. 
Citation: Khalid S (2016) Power Quality Improvement of Constant Frequency Aircraft Electric Power System Using Genetic Algorithm and Neural Network Control Based Control Scheme. J Electr Electron Syst 5: 206. doi:10.4172/2332-0796.1000206

Page 4 of 5

Figure 6. Waveforms show the variations in dc capacitor voltage. Whenever the demand for high load current comes, it releases the energy that in turn increases the compensation current. Later on, it charges and tries to regain its previous set value. By making a simple observation, we can say that compensation current is fulfilling the
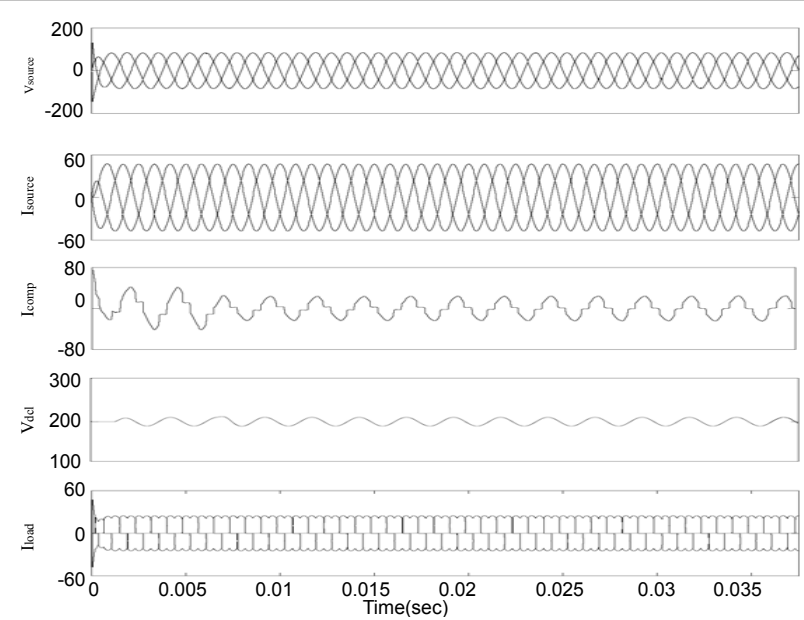

Figure 5: Source voltage, source current, compensation current (phase b), DC link voltage and load current waveforms of active power filter using synchronous reference frame strategy. demand of load current. After the active filtering, the source current and voltage is forced to be sinusoidal.

\section{Comparative analysis of the simulation results}

From Table 1, we can easily say that Synchronous Reference Frame using ANN and Genetic Algorithm (SRF-ANN-GA) has been found best for current and voltage harmonic reduction. When these results have been compared based on compensation time, it has been also found that SRF-ANN-GA strategy is the fastest one.

\section{Conclusion}

This paper has done an acute analysis of traditional and Artificial Intelligent Technique (ANN and Genetic Algorithm applied together) based controller for shunt APF in aircraft power utility of $400 \mathrm{HZ}$. Optimum selection of control strategy based on compensation time and THD has been suggested. Overall Synchronous Reference Frame using ANN\&GA (SRF-ANN-GA) has been observed as an optimum choice. Synchronous Reference Frame Strategy's performance has been

\begin{tabular}{|c|c|c|c|}
\hline Strategy & THD-I (\%) & THD-V (\%) & $\begin{array}{c}\text { Compensation } \\
\text { Time (sec) }\end{array}$ \\
\hline SRF & 2.82 & 1.65 & 0.0100 \\
\hline SRF-ANN-GA & 2.62 & 1.03 & 0.0068 \\
\hline \multicolumn{3}{|c}{ Table 1: Summary of simulation results. }
\end{tabular}
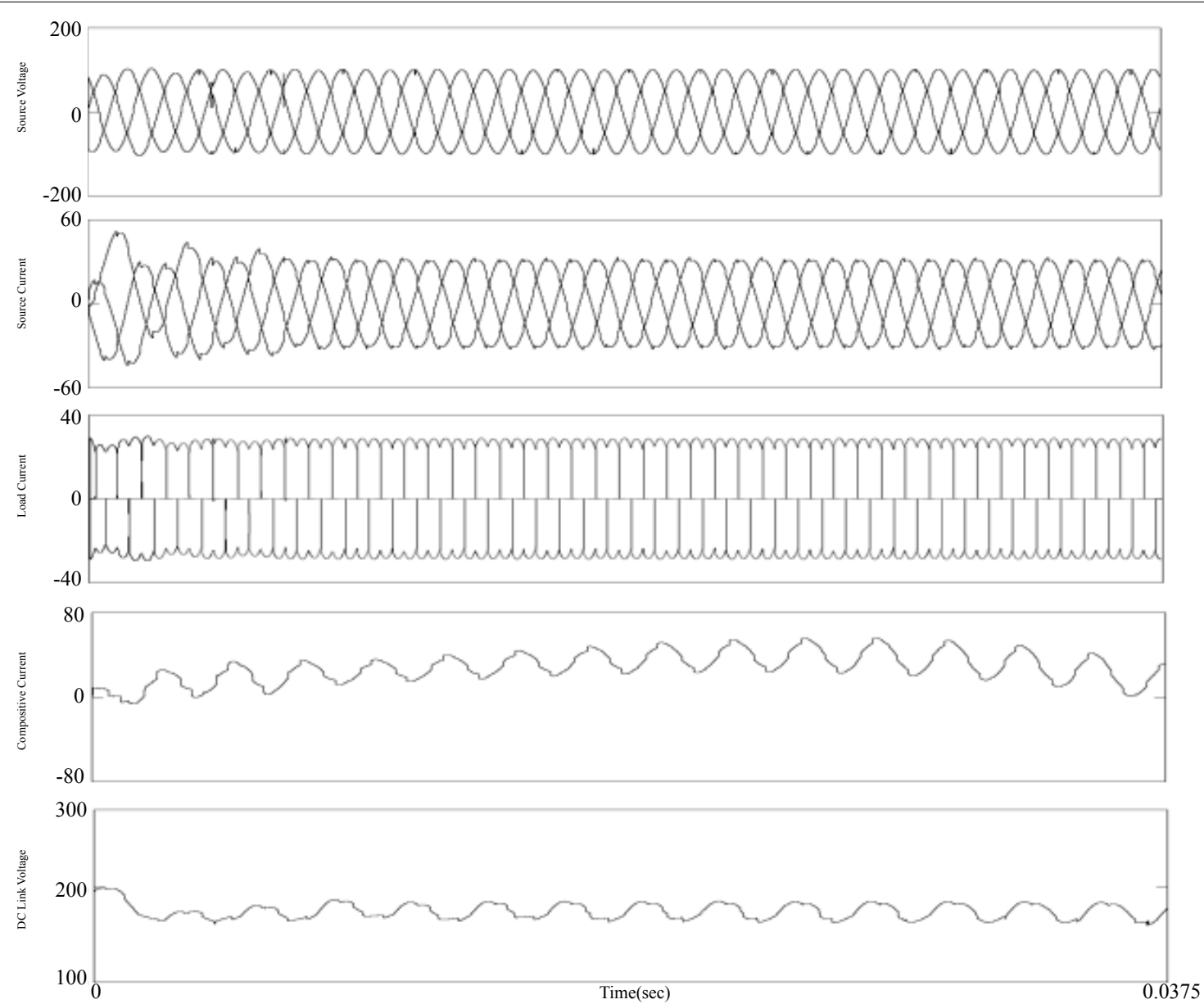

Figure 6: Source voltage, source current, load current and DC link voltage waveforms of active power filter using synchronous reference frame strategy using ANN and genetic algorithm with all three loads connected for aircraft system. 
Citation: Khalid S (2016) Power Quality Improvement of Constant Frequency Aircraft Electric Power System Using Genetic Algorithm and Neural Network Control Based Control Scheme. J Electr Electron Syst 5: 206. doi:10.4172/2332-0796.1000206

improved, which itself an achievement for the case of optimization in traditional strategies.

\section{Parameters}

The aircraft system parameters are [1]:

Three-phase source voltage: $115 \mathrm{~V} / 400 \mathrm{~Hz}$,

Filter capacitor: $5 \mu \mathrm{F}$,

Filter inductor $=0.25 \mathrm{mH}$,

DC capacitor: $4700 \mu \mathrm{F}$,

DC voltage reference: $400 \mathrm{~V}$.

\section{References}

1. Donghua C, Guo T, Xie S, Zhou B (2005) Shunt Active Power Filters Applied in the Aircraft Power Utility. 36th Power Electronics Specialists Conference, PESC 5: 59-63.

2. Saifullah K, Bharti D (2014) Comparative Evaluation of Various Contro Strategies for Shunt Active Power Filters in Aircraft Power Utility of $400 \mathrm{~Hz}$. Majlesi Journal of Mechatronic Systems 3: 1-5

3. Saifullah K, Bharti D (2013) Application of Al techniques in implementing Shunt APF in Aircraft Supply System. Proceeding of SPRINGER - SOCROPROS Conference, IIT-Roorkee 1: 333-341.

4. Guillermin P (1996) Fuzzy logic Applied to Motor Control. IEEE Transactions on Industrial Application 32: 51-56

5. Hew Wooi AHAP, Hamzah A, Mowed HAF (2002) Fuzzy Logic Control of three phase Induction Motor using Field Oriented Control Method. Society of Instrument and Control Engineers, SICE Annual Conference 264-267.

6. Jain SK, Agrawal P, Gupta H (2002) Fuzzy logic controlled shunt active power filter for power quality improvement. IEE Proceedings of the Electric Power Applications 149: 317-328.

7. Norman M, Samsul B, Mohd N, Jasronita J, Omar SB (2004) A Fuzzy logic Controller for an Indirect vector Controlled Three Phase Induction Motor. Proceedings Analog And Digital Techniques In Electrical Engineering, TENCON 2004, Chiang Mai, Thailand 4: 1-4.

8. Afonso JL, Fonseca J, Martins JS, Couto CA (1997) Fuzzy Logic Techniques Applied to the Control of a Three-Phase Induction Motor. Proceedings of the UK Mechatronics Forum International Conference, Portugal. pp. 142-146.

9. Chiewchitboon P, Tipsuwanpom P, Soonthomphisaj N, Piyarat W (2003) Speed Control of Three-phase Induction Motor Online Tuning by Genetic Algorithm Fifth International Conference on Power Electronics and Drive Systems, PEDS 1: 184-188.

10. Kumar P, Mahajan A (2009) Soft Computing Techniques for the Control of an Active Power Filter. IEEE Transactions on Power Delivery 24: 452-461.

11. Ismail KB, Abdeldjebar H, Abdelkrim B, Mazari B, Rahli M (2008) Optimal Fuzzy Self-Tuning of PI Controller Using Genetic Algorithm for Induction Motor Speed Control. Int J of Automation Technology 2: 85-95.
12. Guicheng W, Min Z, Xu X, Changhong J (2006) Optimization of Controller Parameters based on the Improved Genetic Algorithms. IEEE Proceedings of the 6th World Congress on Intelligent Control and Automation, Dalian, China.

13. Radha T, Chelliah TR, Pant M, Ajit A, Grosan C (2010) Optimal gain tuning of $\mathrm{PI}$ speed controller in induction motor drives using particle swarm optimization. Logic Journal of IGPL Advance Access.

14. Joao OP, Bimal BK, Eduardo BSL (2001) A Stator-Flux-Oriented VectorControlled Induction Motor Drive with Space-Vector PWM and Flux-Vecto Synthesis by Neural Networks. IEEE Transaction on Industry Applications 37: 1308-1318.

15. Rajasekaran S, Vijayalakshmi PGA (2005) Neural Networks, Fuzzy Logic and Genetic Algorithm: Synthesis and Applications. Prentice Hall of India, New Delhi, fifth printing.

16. Rojas R (1996) Neural Network - A Systematic Introduction. Spriger-Verlag, Berlin.

17. Zerikat M, Chekroun S (2008) Adaptation Learning Speed Control for a HighPerformance Induction Motor using Neural Networks. Proceedings of World Academy of Science, Engineering and Technology 35: 294-299.

18. Seong-Hwan K, Tae-Sik P, YooJi-Yoon, Gwi-Tae P (2001) Speed-Sensorless Vector Control of an Induction Motor Using Neural Network Speed Estimation. IEEE Transaction on Industrial Electronics 48: 609-614.

19. Saifullah K, Bharti D (2011) Power Quality Issues, Problems, Standards \& their Effects in Industry with Corrective Means. International Journal of Advances in Engineering \& Technology (IJAET) 1: 1-11.

20. Aredes M, Hafner J, Heumann K (1997) Three-Phase Four-Wire Shunt Active Filter Control Strategies. IEEE Transactions on Power Electronics 12: 311-318.

21. Saifullah K, Bharti D (2013) Power quality improvement of constant frequency aircraft electric power system using Fuzzy Logic, Genetic Algorithm and Neura network control based control scheme. International Electrical Engineering Journal (IEEJ) 4: 1098-1104.

22. Saifullah K, Bharti D, Agrawal N, Kumar N (2007) A Review of State of Art Techniques in Active Power Filters and Reactive Power Compensation. National Journal of Technology 3: 10-18.

23. Dugan RC, McGranaghan MF, Beaty HW (1996) Electrical Power Systems Quality. New York: McGraw-Hill.

24. Saifullah K, Bharti D (2010) Power Quality: An Important Aspect. International Journal of Engineering, Science and Technology 2: 6485-6490.

25. IEEE Recommended Practices and Requirements for Harmonic Control in Electrical Power Systems. IEEE Standard 519-1992.

26. Ghosh A, Ledwich G (2002) Power Quality Enhancement Using Custom Power Devices. Boston, MA: Kluwer.

27. Khalid S, Vyas N (2009) Application of Power Electronics to Power System. University Science Press, India.

28. Saifullah K, Bharti D (2013) Comparative Critical Analysis of SAF using Soft Computing and Conventional Control Techniques for High Frequency $(400 \mathrm{~Hz})$ Aircraft System. Proceeding of IEEE - CATCON Conference. 